\title{
A LY-15, a novel cyclic pentapeptide that inhibits B16 cell proliferation and migration and induces cell apoptosis
}

\author{
XUAN WANG, XIANGLI YAO, SHIMING FAN, CHENSHUANG XIANG, \\ RUNJIAO LIU, JUAN FENG, JING HUANG and SHOUXIN LIU

\begin{abstract}
State Key Laboratory Breeding Base-Hebei Province Key Laboratory of Molecular Chemistry for Drug, Hebei University of Science and Technology, Shijiazhuang, Hebei 050018, P.R. China
\end{abstract}

Received August 16, 2017; Accepted January 22, 2018

DOI: $10.3892 / \mathrm{ol} .2018 .8023$

\begin{abstract}
Melanoma is highly resistant to most traditional treatments; therefore, its incidence and mortality rates are rapidly increasing. The effect of a novel sansalvamide $\mathrm{A}$ analogue named LY-15 on the growth and induction of apoptosis in B16 cancer cells was investigated in vitro. The inhibitory effects of LY-15 on B16 cells occurred in a concentration- and time-dependent manner. The B16 cells were cultured in various concentrations of LY-15 (5, 15 and $25 \mu \mathrm{M})$, and the ameliorating effect of LY-15 was evaluated using apoptotic protein markers B-cell lymphoma 2 (Bcl-2), Bcl-2-associated X protein (Bax), caspase-3 and caspase-9. Furthermore, LY-15 effectively inhibited the B16 cell migration, increased the expressions levels of caspase-3, caspase- 9 and the pro-apoptotic Bax, and reduced that of the anti-apoptotic Bcl-2. These findings suggested that LY-15 is a promising chemotherapeutic agent against melanoma by inducing apoptosis through the mitochondrial-associated death pathway. In addition, sansalvamide A analogue LY-15 may a significant therapeutic target for the treatment of malignant melanoma cancer.
\end{abstract}

\section{Introduction}

Malignant melanoma tumor incidence has an annually increasing trend worldwide. Moreover, melanoma accounts for the largest part of skin cancer deaths $(1,2)$. In addition, melanoma is not sensitive to radiotherapy or chemotherapy, and leads a serious problem to clinical treatment. The development of new and highly effective anti-tumor compounds is urgent and challenging. Furthermore, marine microorganisms

Correspondence to: Professor Shouxin Liu, State Key Laboratory Breeding Base-Hebei Province Key Laboratory of Molecular Chemistry for Drug, Hebei University of Science and Technology, 70 Yuhua Road, Shijiazhuang, Hebei 050018, P.R. China E-mail: chsxliu@hotmail.com

Key words: sansalvamide peptide, melanoma, B16 cells, migration, apoptosis and secondary metabolism are promising sources for novel anti-cancer drugs (3). Sansalvamide A, which is a depsipeptide isolated from a marine fungi (Fusarium spp.), exhibits anti-tumor activity on multiple cancer cell lines $(4,5)$ and significant anti-proliferative effects in the National Cancer Institute's panel of 60 cancer cell lines (6). Sansalvamide peptide has anti-tumor activities that became the basis for developing a series of cyclic peptide analogues with $\mathrm{N}$-methylation. The synthesis of sansalvamide $\mathrm{A}$ analogues received sustained attention in recent years. Bromined sansalvamide peptide inhibits pancreatic cancer cell growth through the G0/G1 cell-cycle arrest (7). Methoxylized zygosporamide peptide inhibits B16 cell growth and induces cell apoptosis (8). Cyclic epi-pentadepis peptide induces differentiation and inhibits proliferation in murine melanoma B16 cells (9). Furthermore, the compound LY-15, which was synthesized by the cyclization of the chain pentapeptide in solution, has a molecular formula and weight of $\mathrm{C}_{37} \mathrm{H}_{55} \mathrm{~N}_{5} \mathrm{O}_{5}$ and 649.42 , respectively (Fig. 1). Here, we focused on the effects of LY-15 on the growth and apoptosis of B16 cancer cell lines. Results showed that the compound has greater potency when screened for the growth inhibition of B16 cancer cells, suggesting that LY-15 might be a promising therapeutic agent.

\section{Materials and methods}

Materials. The RPMI 1640 and trypsin-EDTA solution were purchased from Gibco; Thermo Fisher Scientific, Inc., (Waltham, MA, USA). The fetal bovine serum (FBS) was purchased from Bovogen Biologicals Pty Ltd., (Keilor East, Victoria, Australia). The Cell Counting Kit-8 (CCK-8) was purchased from Beijing Zoman Biotechnology Co., Ltd., (Beijing, China) and the bicinchoninic acid kit was purchased from Multi Sciences Co., Ltd., (Shanghai, China). The polyvinylidene fluoride (PVDF) membranes were purchased from Roche Applied Science (Penzberg, Germany). The antibody against $\beta$-actin (polyclonal rabbit anti-mouse) was purchased from Hangzhou HuaAn Biotechnology Co., Ltd., (Hangzhou, China). The antibodies against B-cell lymphoma 2 (Bcl-2), Bcl-2-associated X protein (Bax), caspase-3 and caspase-9 (all polyclonal rabbit anti-mouse) were purchased from Arigo Bio (Taiwan, Xinzhu). The secondary fluorescence anti-body (polyclonal goat anti-rabbit HRP) was purchased from KPL, 
Inc., (Gaithersburg, MD, USA). The sansalvamide analogue LY-15 was developed in Hebei Province Key Laboratory of Molecular Chemistry for Drug (Shijiazhuang, China).

Cancer cell line and cell culture. B16 cancer cells were selected for the present study. The B16 cell line was obtained from the Research Center of the Fourth Hospital of Hebei Medical University (Shijiazhuang, China). The cells were grown in RPMI 1640 medium with 10\% heat-inactivated FBS and $100 \mu \mathrm{g} / \mathrm{ml}$ penicillin and streptomycin. The cell line was grown in a humidified atmosphere of $95 \% \mathrm{O}_{2}$ and $5 \% \mathrm{CO}_{2}$ at $37^{\circ} \mathrm{C}$ and the cells were periodically seeded into $25 \mathrm{~cm}^{2}$ flasks. The media was changed every second or third day. For the experiments, the cells were grown to $80-90 \%$ confluence, digested with trypsin-EDTA, and plated in $25 \mathrm{~cm}^{2}$ flasks, and the media was changed every second or third day on 6- or 96-well plates.

Concentration-dependent effect of LY-15 on B16 cell growth inhibition. LY-15 was dissolved in DMSO and diluted with serum-free medium to prepare solutions of 1,000, 100, 10 and $1 \mu \mathrm{M}$. Single-cell suspensions of B16 cells were prepared and adjusted to the indicated concentrations. The cells were inoculated in 96-well plates (100 $\mu \mathrm{l} /$ well) with 5,000 cells/well. After overnight inoculation for cell adherence, the old medium was discarded and replaced with fresh medium with different concentrations of $100,50,25,15,10,5$ and $1 \mu \mathrm{M}$. Each group was placed into six wells, and a $1 \%$ DMSO group was simultaneously prepared as the control. The CCK- 8 method was used to calculate the percentage growth of the B16 cells treated with various concentrations of LY-15 for $24 \mathrm{~h}$.

Time-dependent effect of LY-15 on B16 cell growth inhibition. Upon reaching $80 \%$ confluence, the cells were digested with trypsin-EDTA and serum-free medium was used to make a single-cell suspension. The cells were seeded over night in 96-well plates at a concentration of 3,000 cells/well. The wells were then replaced with fresh complete medium and treated with $10 \mu \mathrm{M}$ LY-15. The percentage growth of the B16 cells treated for 24, 48, 72, 96 and $120 \mathrm{~h}$ was calculated.

Cell scratch test. Five uniform lines were drawn behind the 6 -well plates using a marker pen. The single-cell suspension was seeded in the 6 -well plates at a concentration of 200,000 cells/well. After $6 \mathrm{~h}, 20 \mu \mathrm{l}$ pipette tips were used to draw through the marker lines. The wells were washed with PBS thrice and fresh media $(2 \mathrm{ml} /$ well $)$ with different concentrations at $1,2,5$ and $15 \mu \mathrm{M}$ were added; moreover, $1 \%$ DMSO was added to the last well that was simultaneously prepared as the control. Images were captured at 0 and $24 \mathrm{~h}$ in the same position. We examined the effect of LY-15 on B16 cell migration using the cell scratch test.

Flow cytometric analysis of apoptotic cell death. At 80-90\% confluence, the cells were treated with 2, 5, 10, 15 and $25 \mu \mathrm{M}$ LY-15 for $24 \mathrm{~h}$, and a control group was prepared. The treated and untreated cells were harvested, washed twice with PBS, and mixed with 1 xbuffer $100 \mu \mathrm{l}$. After blending the cells, $10 \mu \mathrm{l}$ FITC and $5 \mu \mathrm{l}$ propidium iodide (PI) were added. The cells were kept in a dark place for $30 \mathrm{~min}$.
Detection of caspase-3 and caspase-9 expressions using western blot analysis. The cells at 70-80\% confluence were treated with 5, 15 and $25 \mu \mathrm{M}$ of LY-15 for $24 \mathrm{~h}$, and a control group was prepared. Proteins were separated using SDS-polyacrylamide gel electrophoresis. Equal amounts of protein (50 $\mu \mathrm{g} / \mathrm{sample})$ from B16 cells treated with LY-15 were loaded to $10 \%$ SDS-PAGE in an electrophoresis buffer in a Bio-Rad slab gel apparatus. The proteins were then transferred to a PVDF membrane under the conditions of $80 \mathrm{~V}$ for $20 \mathrm{~min}, 100 \mathrm{~V}$ for $90 \mathrm{~min}$ and $200 \mathrm{~mA}$ for $120 \mathrm{~min}$. Next, the membranes were incubated in antibody dilution solution (rabbit anti-mouse bax, bcl-2, caspase-3 and caspase-9; 1:1,000 and $\beta$-actin; $1: 3,000)$ overnight at $4^{\circ} \mathrm{C}$. The blots were then incubated with the secondary antibody $(1: 3,000)$ for $1 \mathrm{~h}$ at $37^{\circ} \mathrm{C}$. Results were obtained using the Aplegen Omega Lum C Gel Imaging System (Gel Company, Inc., San Francisco, CA). Concetration of protein was calculated by Image J (NIH, USA).

Statistical analysis. Statistical analysis was performed using SAS software (SAS Institute, Inc., Cary, NC, USA) and $\mathrm{R}$ programming language. Values were expressed as the mean \pm standard error and were analyzed using one-way ANOVA followed by Tukey's post hoc test. $\mathrm{P}<0.05$ was considered to indicate a statistically significant difference. All statistical analyses were conducted using Graphpad Prism v5 (GraphPad Software, Inc., La Jolla, CA, USA).

\section{Results}

LY-15 exhibits a concentration-dependent effect on B16 cell growth. The apoptosis and death of B16 cells were induced by the LY-15 treatment in various concentrations of $(1,5,10,15$, 25, 50 and $100 \mu \mathrm{M}$ ) for $24 \mathrm{~h}$. Moreover, the proliferation rate of the B16 cells showed a decreasing trend. Compared with the control group, no significant difference was identified for the proliferation rate of the $1 \%$ DMSO group $(\mathrm{P}>0.05)$, whereas those for the treatment of the B16 cells with 100, 50, 25, 15 and $10 \mu \mathrm{M}$ LY-15 significantly decreased $(\mathrm{P}<0.001$ for all treatment groups, Fig. 2). The morphological changes in B16 cells were observed via optical microscopy (Fig. 3). The B16 cells treated with $15 \mu \mathrm{M}$ LY-15 for $24 \mathrm{~h}$ exhibited morphological changes, including decreased cell density, separation of the adjacent cells, and cell shrinkage.

LY-15 exhibits a time-dependent effect on B16 cell growth. The proliferation rate of the B16 cells with the treatment of the concentration of $100,50,25,15,10,5$ and $1 \mu \mathrm{M}$ LY-15 was investigated. The concentration $10 \mu \mathrm{M}$ LY-15 was significantly reduced in a time-dependent manner compared with that of the control group $(\mathrm{P}<0.001$ for all time-dependent groups, Fig. 4). The results showed that LY-15 time-dependently inhibits the growth of B16 cells.

LY-15 inhibits the cell migration of B16 cells. Compared with the control group, no obvious difference was identified in the cell migration of the 1\% DMSO group. The cell migration of B16 was weakened by the LY-15 treatments with concentrations of $1,2,5$ and $15 \mu \mathrm{M}$ for $24 \mathrm{~h}$. The ability of cell migration gradually decreased as the concentration increased. The cell migration changes were observed under optical 

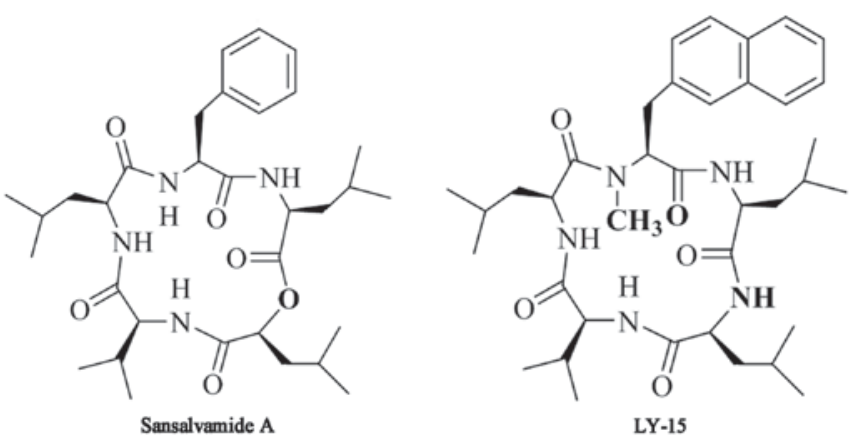

Figure 1. Structures of sansalvamide A and its analogue, LY-15.

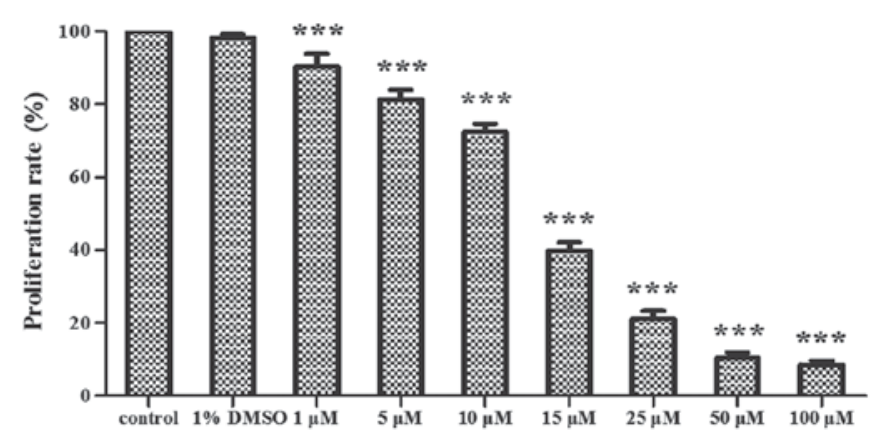

Figure 2. Compared with the control group, no significant difference was identified in the proliferation rate of the $1 \%$ DMSO group $(\mathrm{P}>0.05)$. All administration groups present significant differences compared with the control group $(\mathrm{P}<0.001)$. Besides, there was no significant difference between 50 and $100 \mu \mathrm{M}(\mathrm{P}>0.05)$. The overall average is not exactly equal $(\mathrm{F}=943.214$, $\mathrm{P}<0.001){ }^{* * * *} \mathrm{P}<0.001$.
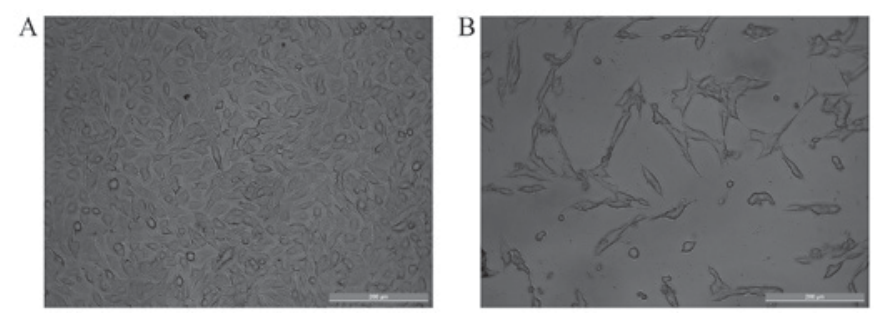

Figure 3. (A) B16 cells of the control group exhibiting vigorous and homogenous growth; magnification, x100. (B) B16 cells treated with $15 \mu \mathrm{M}$ LY-15 for $24 \mathrm{~h}$ exhibiting marked morphological changes, including decreased cell density, separation of the adjacent cells, and rounding of the cells; magnification, $\mathrm{x} 100$.

microscopy (Fig. 5). The cells lost their ability to migrate at LY-15 concentration of $15 \mu \mathrm{M}$.

LY-15 promotes the apoptosis of B16 cells. The ability of LY-15 to induce apoptosis was revealed by analyzing the cell samples using flow cytometry. The cells in the early stage of apoptosis were detected by Annexin V, whereas those in the late apoptosis were assessed by PI staining. The $1 \%$ DMSO group did not show significant difference in apoptosis compared with the control group. The early and late apoptosis stages of the B16 cells gradually increased with the treatment of LY-15 $(5,15$ and $25 \mu \mathrm{M})$ for $24 \mathrm{~h}$ (Fig. 6). The percentage of apoptotic cells in the control group was 1.46; however, the proportion of apoptotic cells reached 8.57 in the group treated with $15 \mu \mathrm{M} \mathrm{LY}-15$ for $24 \mathrm{~h}$.

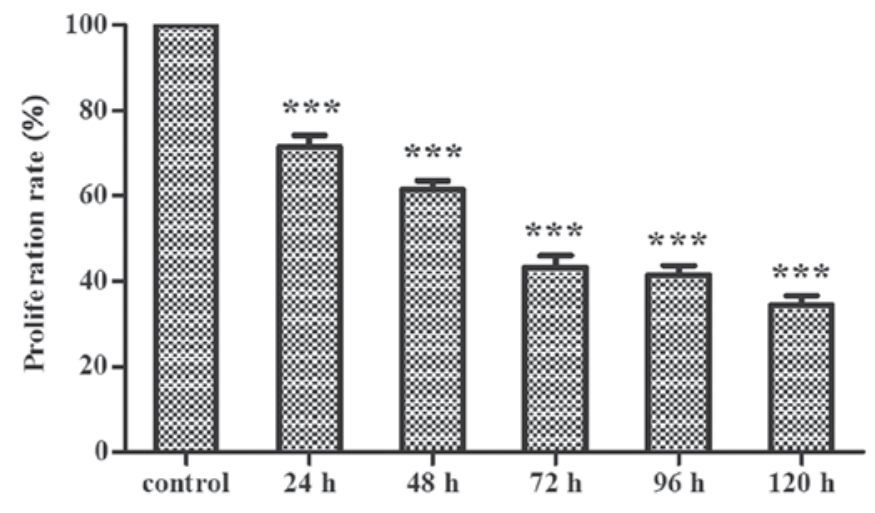

Figure 4. The B16 cells treated with $10 \mu \mathrm{M}$ LY-15 showed significant differences in various time points compared with the control group $(\mathrm{P}<0.001)$. Besides, there was no significant difference between 72 and $96 \mathrm{~h}(\mathrm{P}>0.05)$. The overall average is not exactly equal $(\mathrm{F}=382.334, \mathrm{P}<0.001){ }^{* * * *} \mathrm{P}<0.001$.

\section{LY-15 induces apoptosis of B16 cells through the mitochondrial} pathway. At the present stage of the study, the results of the western blot analysis showed an increasing trend in the expression of Bax, whereas that of $\mathrm{Bcl}-2$ showed the opposite. Caspase-3 and caspase-9 expressions were analyzed using western blot analysis and further confirmed that LY-15 induces apoptosis. The expression levels of caspase- 3 and caspase- 9 in the B16 cells increased with the treatments of 5, 15 and $25 \mu \mathrm{M}$ LY-15 (Fig. 7). All results revealed that LY-15 induces the B16 cells apoptosis through a mitochondrial pathway.

\section{Discussion}

Melanoma remains one of the most common cancers in western countries and is the main contributor to skin cancer-related deaths $(10,11)$. Melanoma has a strong resistance and high metastasis and mortality rates $(12,13)$. Studies were conducted on the synthesis and bioactivities of various sansalvamide A derivatives $(14,15)$. The compound LY-15 is a novel sansalvamide A analogue that was recently synthesized by our group. Based on the specific structures of cyclic peptides, their bioactivities differ when the amino acid sequences are changed; moreover, the analogues are lipophilic and exhibit rapid membrane absorption (7). Accordingly, we studied the effects of the compound LY-15 on melanoma cell B16 and its potential molecular mechanisms to provide references for its clinical applications in melanoma therapy.

Melanoma cells exhibit strong proliferation, viability and malignancy. The curative effects of chemotherapeutic drugs against melanoma are clinically challenged because of their ability to resist apoptosis. Therefore, melanoma treatment studies have focused on finding and selecting a novel effective compound. Studies at this stage reported that the growth rate of B16 cells is significantly inhibited by the compound LY-15. Data showed that the effect of the compound LY-15 on the growth of B16 cells is concentration-(100, 50, 25, 15, 10, 5 and $1 \mu \mathrm{M})$ and time-dependent. Moreover, the cell proliferation rate was only $39.74 \%$ in the B16 cells cultured with $15 \mu \mathrm{M}$ LY-15 for $24 \mathrm{~h}$, indicating that the treatment has a remarkable effect. The effect of LY-15 on non-cancerous cells has been investigated preliminarily. The proliferation of 293t cell still kept more than $85 \%$ even as LY-15 with the concentration 


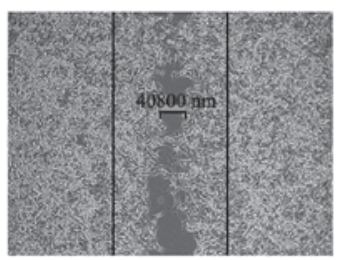

Control

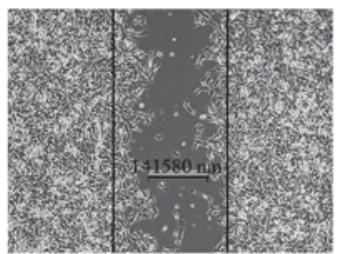

$2 \mu \mathrm{M}$

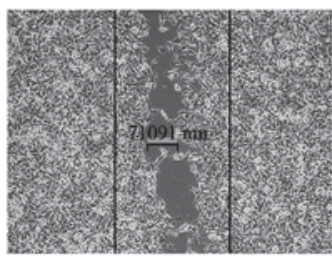

$1 \%$ DMSO

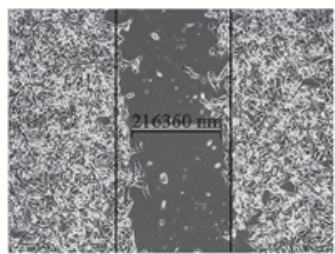

$5 \mu \mathrm{M}$

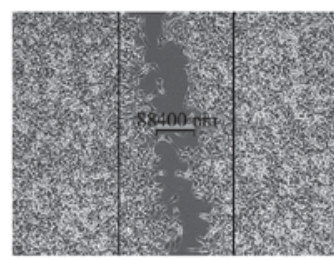

$1 \mu \mathrm{M}$

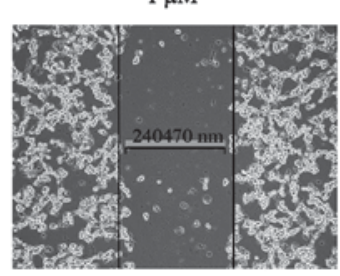

$15 \mu \mathrm{M}$

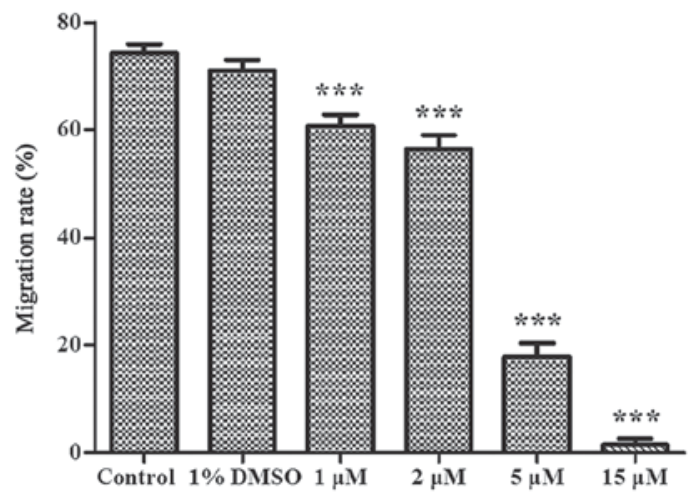

Figure 5. No significant difference was identified in the migration rate of the $1 \%$ DMSO group compared with that of the control group (P>0.05). LY-15 inhibited the cell migration of B16 cells. All administration groups present significant differences compared with the control group $(\mathrm{P}<0.001)$. Besides, there was no significant difference between 1 and $2 \mu \mathrm{M}(\mathrm{P}>0.05)$. The overall average is not exactly equal $(\mathrm{F}=622.366, \mathrm{P}<0.001) .{ }^{* * *} \mathrm{P}<0.001$.
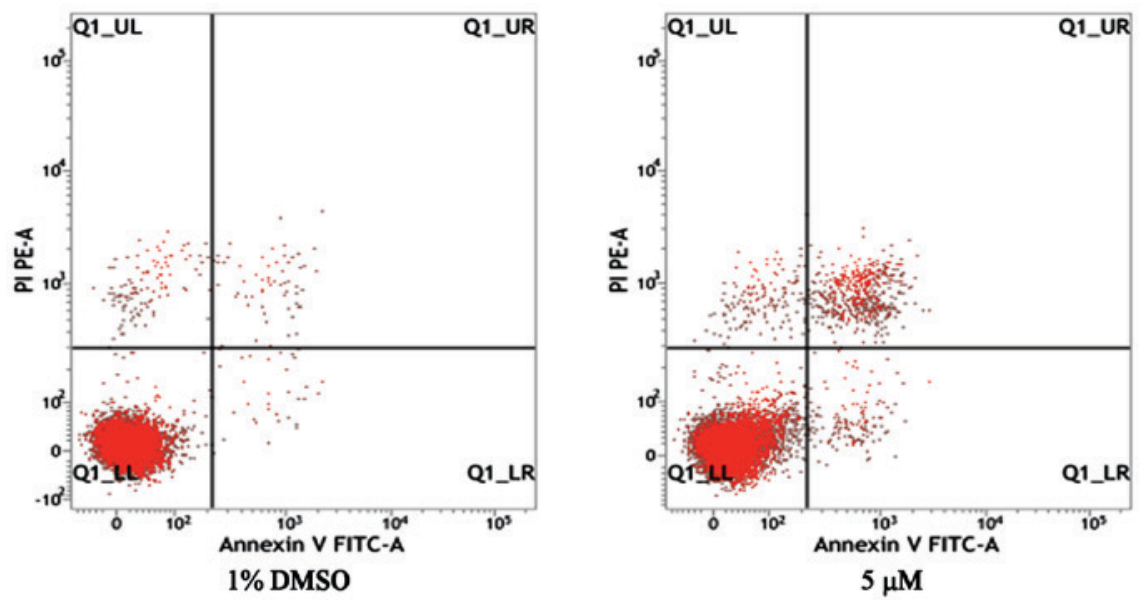

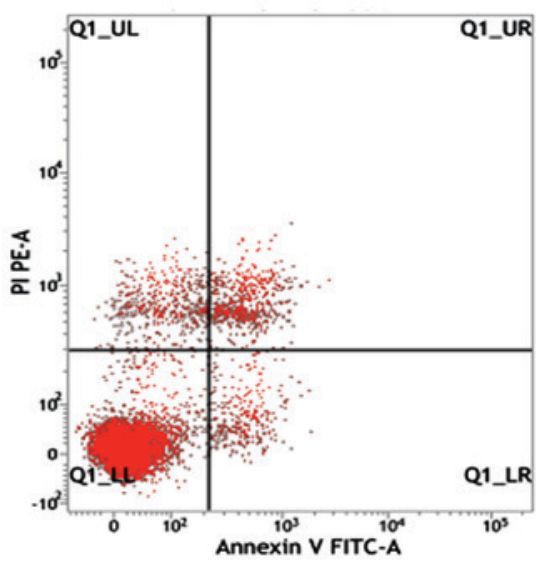

$15 \mu \mathrm{M}$

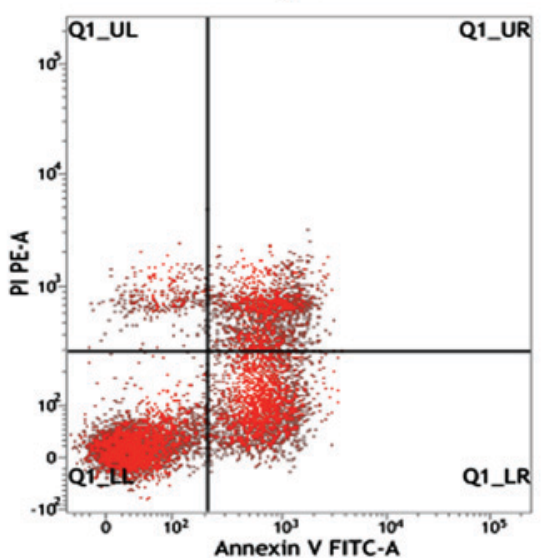

$25 \mu \mathrm{M}$

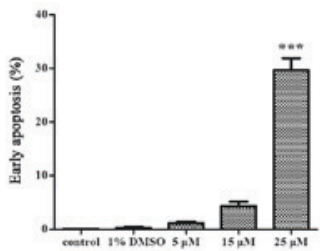

Early apoptosis

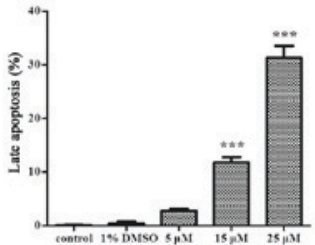

Late apoptosis

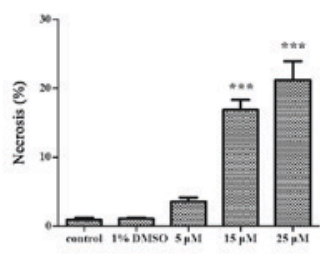

Necrosis

Figure 6. No significant difference was identified in the apoptosis rate of the $1 \%$ DMSO and $5 \mu \mathrm{M}$ groups compared with the control group (P>0.05). In the stage of early apoptosis, $25 \mu \mathrm{M}$ group present significant differences compared with the control group $(\mathrm{P}<0.001)$. In the stage of late apoptosis and necrosis, 15 and $25 \mu \mathrm{M}$ groups present significant differences compared with the control group $(\mathrm{P}<0.001)$. The overall average is not exactly equal $(\mathrm{P}<0.001)$. ${ }^{* * *} \mathrm{P}<0.001$. 


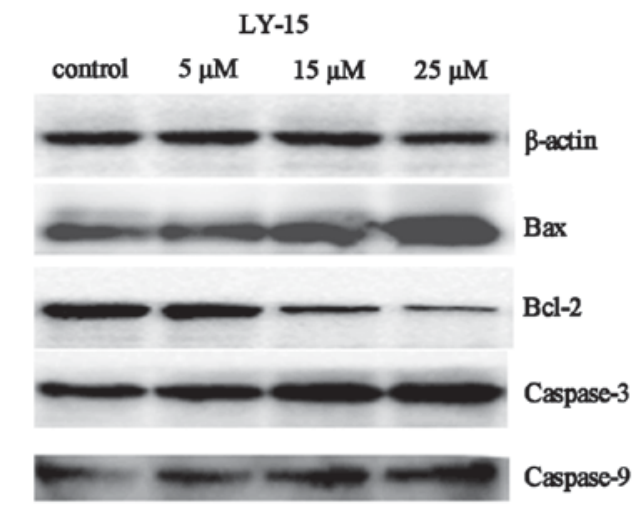

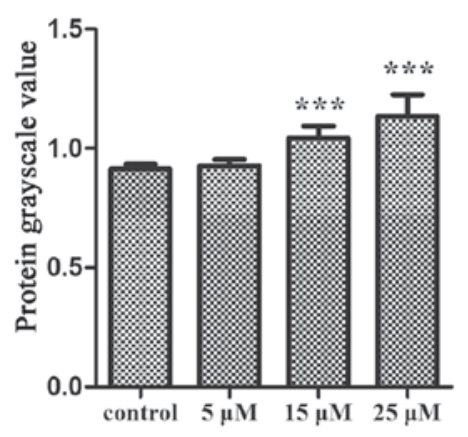

Bax

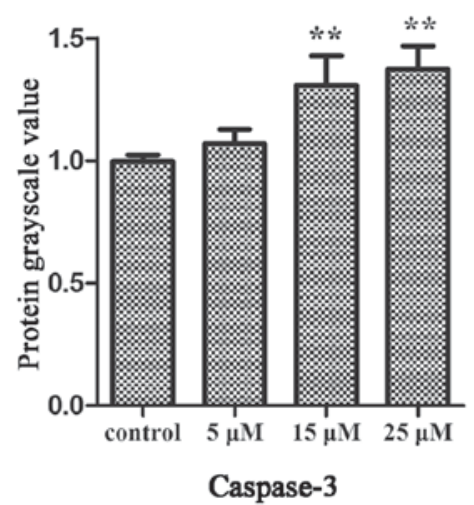

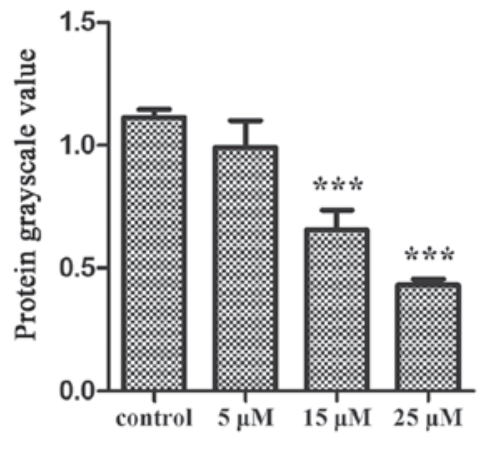

Bcl-2

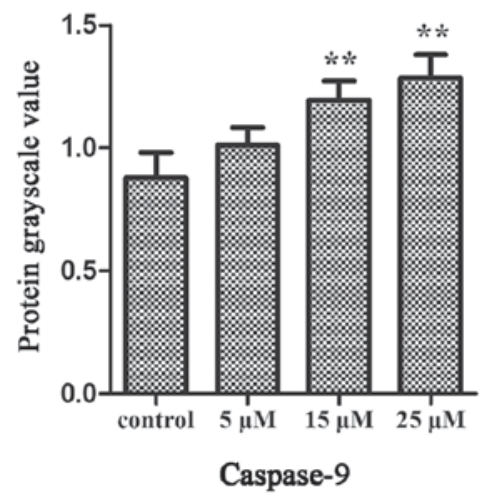

Figure 7. No significant difference was identified in the protein grayscale value of the $5 \mu \mathrm{M}$ group compared with that of the control group (P>0.05). Besides, there was no significant difference between 15 and $25 \mu \mathrm{M}(\mathrm{P}>0.05)$. Compared with the control group, 15 and $25 \mu \mathrm{M}$ groups present significant differences. For Bax and Bcl-2, $\mathrm{P}<0.001$. For caspase-3 and caspase-9, $\mathrm{P}<0.01$. The overall average is not exactly equal $(\mathrm{P}<0.001){ }^{* * *} \mathrm{P}<0.01 ;{ }^{* * * *} \mathrm{P}<0.001$.

$50 \mu \mathrm{M}$ treated the cell. But, the details and the toxicities for more non-cancerous cell need to investigate further.

The cellular morphology of B16 treated with $15 \mu \mathrm{M} \mathrm{LY}-15$ showed that the cell density was sharply reduced over time, and the cell exhibited a collection and spindle interstitial substance morphology. Moreover, B16 cells were significantly and slightly differentiated. Based on the flow cytometry data for B16 cells treated with $5 \mu \mathrm{M} \mathrm{LY}-15$ for $24 \mathrm{~h}$, cell apoptosis is significant, and the values of the early and late apoptotic stages of the B16 cells changed in a dose-dependent manner. These results revealed that the inhibition of B16 proliferation by the compound LY-15 is directly related to cell differentiation and apoptosis. Scratch wound healing assay was conducted to study the effect of LY-15 on the migration of B16 cells. The results showed that B16 cell migration was significantly inhibited by the $5 \mu \mathrm{M} \mathrm{LY}-15$. In order to describe the details of tumor cell movement, the cell invasion and cell cycle will be key work for further investigation. After the $15 \mu \mathrm{M} \mathrm{LY}-15$ treatment, the cells turned sparse and apoptotic.

Apoptosis is programmed cell death and is an important part of the normal cell development and function of organisms. This process is triggered in a cell either through an extrinsic or intrinsic pathway (16). Protein Bcl-2 inhibits apoptosis in various cell types (17) and Bax is a protein that promotes cell apoptosis. Caspases play critical roles in apoptosis initiation and execution. Caspase-9, which is from the caspase family, is an initiator protein that drives caspase-3 to execute cell apoptosis. In investigating the anti-apoptotic potential of LY-15, the LY-15 administration significantly elevated the levels of the apoptotic marker proteins Bax, caspase- 3 and caspase-9; whereas the anti-apoptotic factor Bcl-2 level was reduced following the treatment with various LY-15 concentrations $(5,15$ and $25 \mu \mathrm{M})$. These results support 
the hypothesis that LY-15 may inhibit B16 cell growth via the mitochondrial pathway, which induces apoptosis.

In conclusion, the results of this study showed that the compound LY-15 induces apoptosis in B16 cells and effectively inhibits their migration. Considering the invasiveness and drug resistance of melanoma, LY-15 provides a promising route for improving melanoma treatments.

\section{Acknowledgements}

The authors received financial assistance from the Basic Research Program of China (grant number 2010CB512007, 2012CB723501), the Natural Science Foundation of China (grant number 3047204, 3087313).

\section{References}

1. Clark WH Jr, From L, Bernardino EA and Mihm MC: The histogenesis and biologic behavior of primary human malignant melanomas of the skin. Cancer Res 29: 705-727, 1969.

2. Rigel DS, Russak J and Friedman R: The evolution of melanoma diagnosis: 25 years beyond the ABCDs. CA Cancer J Clin 60: 301-316, 2010

3. Gupta AP, Pandotra P, Sharma R, Kushwaha M and Gupta S: Chapter 8-Marine resource: A promising future for anticancer drugs. Stud Nat Prod Chem 40: 229-325, 2013.

4. Styers TJ, Kekec A, Rodriguez R, Brown JD, Cajica J, Pan PS, Parry E, Carroll CL, Medina I, Corral R, et al: Synthesis of sansalvamide A derivatives and their cytotoxicity in the MSS colon cancer cell line HT-29. Bioorg Med Chem 14: 5625-5631, 2006.

5. Otrubova K, Lushington G, Vander Velde D, McGuire KL and McAlpine SR: Comprehensive study of sansalvamide A derivatives and their structure-activity relationships against drug-resistant colon cancer cell lines. J Med Chem 51: 530-544, 2008.

6. Belofsky GN, Jensen PR and Fenical W: Sansalvamide: A new cytotoxic cyclic depsipeptide produced by a marine fungus of the genus Fusarium. Tetrahedron Lett 40: 2913-2916, 1999.
7. Ujiki MB, Milam B, Ding XZ, Roginsky AB, Salabat MR, Talamonti MS, Bell RH, Gu W, Silverman RB and Adrian TE: A novel peptide sansalvamide analogue inhibits pancreatic cancer cell growth through G0/G1 cell-cycle arrest. Biochem Biophys Res Commun 340: 1224-1228, 2006.

8. Zhang G, Liu S, Liu Y, Wang F, Ren J, Gu J, Zhou K and Shan B: A novel cyclic pentapeptide, H-10, inhibits B16 cancer cell growth and induces cell apoptosis. Oncology Lett 8: 248-252, 2014.

9. Liu Y, Zhang G, Wang H, Liu S, Chen J, Zhao L, Li J and Shan B: Novel cyclic pentapeptide $\mathrm{H}-15$ induces differentiation and inhibits proliferation in murine melanoma B16 cells. Oncology Lett 11: 1251-1255, 2016.

10. Park SY, Cho SJ, Kwon HC, Lee KR, Rhee DK and Pyo S: Caspase-independent cell death by allicin in human epithelial carcinoma cells: Involvement of PKA. Cancer Lett 224: 123-132, 2005.

11. Loescher LJ, Janda M, Soyer HP, Shea K and Curiel-Lewandrowski C: Advances in skin cancer early detection and diagnosis. Semin Oncol Nurs 29: 170-181, 2013.

12. Siegel RL, Miller KD and Jema A: Cancer statistics. CA Cancer J Clin 66: 7-30, 2016.

13. Kwon SJ, Lee JH, Moon KD, Jeong IY, Ahn DU, Lee MK and Seo KI: Induction of apoptosis by isoegomaketone from perilla frutescens L. in B16 melanoma cells is mediated through ROS generation and mitochondrial-dependent, -independent pathway. Food Chem Toxicol 65: 97-104, 2014.

14. Pan PS, Vasko RC, Lapera SA, Johnson VA, Sellers RP, Lin CC, Pan CM, Davis MR, Ardi VC and McAlpine SR: A comprehensive study of Sansalvamide A derivatives: The structure-activity relationships of 78 derivatives in two pancreatic cancer cell lines. Bioorg Med Chem 16: 5806-5825, 2009.

15. Pan PS, McGuire KL and McAlpine SR: Identification of sansalvamide an analog potent against pancreatic cancer cell lines. Bioorg Med Chem Lett 17: 5072-5077, 2007.

16. Venkatesan RS and Sadiq AM: Effect of morin-5'-sulfonic acid sodium salt on the expression of apoptosis related proteins caspase 3, Bax and Bcl 2 due to the mercury induced oxidative stress in albino rats. Biomed Pharmacother 85: 202-208, 2017.

17. Zhang SD, Shan L, Li W, Li HL and Zhang WD: Isochamaejasmin induces apoptosis in leukemia cells through inhibiting $\mathrm{Bcl} 2$ family proteins. Chin J Nat Med 13: 660-666, 2015. 